ARTICLE

DOI: $10.1038 / \mathrm{s} 41467-018-05441-9$

\title{
Cysteine-mediated decyanation of vitamin B12 by the predicted membrane transporter BtuM
}

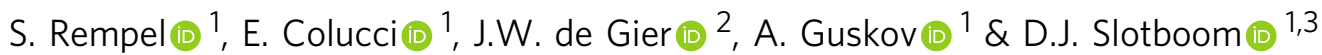

Uptake of vitamin B12 is essential for many prokaryotes, but in most cases the membrane proteins involved are yet to be identified. We present the biochemical characterization and high-resolution crystal structure of BtuM, a predicted bacterial vitamin B12 uptake system. BtuM binds vitamin B12 in its base-off conformation, with a cysteine residue as axial ligand of the corrin cobalt ion. Spectroscopic analysis indicates that the unusual thiolate coordination allows for decyanation of vitamin B12. Chemical modification of the substrate is a property other characterized vitamin B12-transport proteins do not exhibit.

\footnotetext{
${ }^{1}$ Groningen Biomolecular and Biotechnology Institute (GBB), University of Groningen, Nijenborgh 4, 9474 AG Groningen, The Netherlands. ${ }^{2}$ Department of Biochemistry and Biophysics, Stockholm University, 10691 Stockholm, Sweden. ${ }^{3}$ Zernike Institute for Advanced Materials, University of Groningen, 
C obalamin $(\mathrm{Cbl})$ is one of the most complex cofactors (Supplementary Figure 1a) known, and used by enzymes catalyzing for instance methyl-group transfer and ribonucleotide reduction reactions ${ }^{1,2}$. For example, in the methionine synthase $\mathrm{MetH}$, the cofactor is used to transfer a methyl moiety onto L-homocysteine to produce L-methionine ${ }^{1,3}$. Many bacteria require Cbl for survival ${ }^{1,2,4,5}$, but only a small subset of prokaryotic species can produce this molecule de novo, via either an aerobic or anaerobic pathway ${ }^{4,5}$. Roughly two thirds of archaea and eubacteria are Cbl-auxotrophs that rely on uptake of either $\mathrm{Cbl}$ or its precursor cobinamide $\mathrm{e}^{2,5,6}$ (Cbi, Fig. 1a, Supplementary Figure 1b). Dependence on uptake has probably evolved, because synthesis of $\mathrm{Cbl}$ involves roughly 30 different enzymes and is energetically costly. Gram-negative bacteria require the TonBdependent transporter $\mathrm{BtuB}^{1}$ to transport $\mathrm{Cbl}$ across the outer membrane (Supplementary Figure 1c). For subsequent transport of vitamin B12 across the cytoplasmic membrane, the only characterized bacterial uptake system is the $\mathrm{ABC}$ transporter BtuCDF, which is predicted to be present in approximately $50 \%$ of Cbl-auxotrophic bacteria ${ }^{5,7}$. Many Cbl-auxotrophic Gramnegative bacteria do not encode BtuCDF, whereas they do contain BtuB. Metabolic reconstruction and chromosomal context analyses, e.g. co-localization with the gene for BtuB, have identified potential alternative inner membrane vitamin B12 transporters, one of which is $\mathrm{BtuM}^{5}$. BtuM homologues are small membrane proteins of $\sim 22 \mathrm{kDa}$, and found predominantly in Gram-negative species, distributed mostly over $\alpha-, \beta-$, and $\gamma$-proteobacteria (Supplementary Data 1).

Here, we sought to characterize the predicted vitamin B12 transporter BtuM from Thiobacillus denitrificans $\left(\mathrm{BtuM}_{\mathrm{Td}}\right)$. We show that $\mathrm{BtuM}_{\mathrm{Td}}$ is involved in transport of $\mathrm{Cbl}$ in vivo and we solved its structure to $2 \AA$ resolution. A cobalt-cysteine interaction allows for chemical modification of the substrate prior to translocation, which is a rare feature among uptake systems.

\section{Results}

BtuM $_{\mathrm{Td}}$ supports vitamin B12-dependent growth. To test experimentally whether $\mathrm{BtuM}_{\mathrm{Td}}$ is a potential Cbl-transporter, we constructed an Escherichia coli triple knockout strain, E. coli $\triangle \mathrm{FEC}$, based on Cadieux et al. ${ }^{8}$. In this strain, the gene encoding the Cblindependent methionine synthase, $\operatorname{MetE}^{9}$, is deleted. The metE deletion makes it impossible for $E$. coli $\triangle \mathrm{FEC}$ to synthesize methionine, unless it can import $\mathrm{Cbl}^{8,9}$. In that case, L-methionine can be synthesized using the Cbl-dependent methionine synthase, $\mathrm{MetH}^{3,8}$. E. coli $\triangle \mathrm{FEC}$ has additional deletions in $b t u F$ and $b t u C$, encoding subunits of the endogenous Cbl-transporter $\mathrm{BtuCDF}^{7,8}$. Therefore, E. coli $\triangle$ FEC cannot import Cbl, prohibiting MetHmediated L-methionine synthesis. Consequently, E. coli $\triangle \mathrm{FEC}$ can grow only if L-methionine is present or if vitamin B12 import is restored by (heterologous) expression of a Cbl-transport system ${ }^{8}$. The phenotype of $E$. coli $\triangle \mathrm{FEC}$ was confirmed in growth assays (Supplementary Figure 2a). Cells that are not expressing any Cbltransporter did not exhibit substantial growth in methionine-free medium, whereas cells complemented with an expression plasmid for BtuCDF grew readily (Fig. 1b). Cells expressing BtuM $\mathrm{M}_{\mathrm{Td}}$ had a similar growth phenotype, indicating that $\mathrm{BtuM}_{\mathrm{Td}}$ is a potential transporter for vitamin B12 (Fig. 1b).

Crystal structure of $\mathrm{BtuM}_{\mathrm{Td}}$ bound to vitamin B12. The BtuM family contains an invariably conserved cysteine residue (Supplementary Figure 3a). In $\mathrm{BtuM}_{\mathrm{Td}}$, this cysteine is located at position 80 , and mutation to serine abolishes the ability of the protein to complement the E. coli $\triangle$ FEC strain (Fig. 1b). To investigate the role of the cysteine, we solved a crystal structure at $2 \AA$ resolution of BtuM $_{\mathrm{Td}}$ in complex with Cbl. Data collection as well as refinement statistics are summarized in Table $1 . \mathrm{BtuM}_{\mathrm{Td}}$ consists of six transmembrane helices with both termini located on the predicted cytosolic side (Fig. 1c). The amino acid sequences of BtuM proteins are not related to any other protein ${ }^{5}$ but, surprisingly, $\mathrm{BtuM}_{\mathrm{Td}}$ resembles the structure of $\mathrm{S}$ components from energy-coupling factor (ECF)-type $\mathrm{ABC}$ transporters $^{10}$ (Supplementary Figure 4 and Supplementary Table 1). In contrast to BtuM proteins, ECF-type ABC transporters are predominantly found in Gram-positive bacteria. They are multi-subunit complexes consisting of two peripheral ATPases and two transmembrane components (EcfT and Scomponent $)^{10,11}$. EcfT and the ATPases together form the socalled ECF-module. S-components bind the transported substrate, and dynamically associate with the ECF-module to allow substrate translocation ${ }^{10,12-14}$. Intriguingly, no homologues of EcfT could be found in T. denitrificans. In addition, all ABC-type ATPases encoded by the organism are predicted to be part of classical ABC transporters, and not ECF transporters. Therefore, we conclude that the organism does not encode an ECF-module, and hypothesize that solitary $\mathrm{BtuM}_{\mathrm{Td}}$ may be responsible for $\mathrm{Cbl}$ uptake. This hypothesis is supported by the ability of BtuM $_{\mathrm{Td}}$ to transport vitamin B12 when expressed heterologously in E. coli $\triangle F E C$. Importantly, E.coli also does not encode an ECFmodule ${ }^{11}$, hence BtuM $_{\mathrm{Td}}$ cannot interact with a module from the host, and BtuM $\mathrm{Td}_{\mathrm{Td}}$ must be able to support $\mathrm{Cbl}$ uptake using a different mechanism than that of ECF transporters ${ }^{10,11}$. In a few cases, the biotin-specific S-component BioY ${ }^{15}$ has also been found in organisms lacking an ECF-module and was shown to mediate transport without the need for an ECF-module ${ }^{15}$. However, organisms encoding only BioY without an ECF-module are rare $^{15}$, and in the large majority of organisms BioY is associated with an ECF-module ${ }^{11}$. In contrast, BtuM homologues (apart from one exception) are found exclusively in organisms lacking an ECF-module (Supplementary Data 1).

Further experiments, for instance using purified protein reconstituted in proteoliposomes, are required to test whether BtuM $_{\mathrm{Td}}$ also catalyses transport in vitro without any additional component involved. However, the in vivo assay gives a very strong indication that $\mathrm{BtuM}_{\mathrm{Td}}$ is a transporter itself, as the protein was expressed in a heterologous host that does not contain any ECF-module or S-component. Similar in vivo experiments have been used extensively in the past to identify other transporters (for instance ref. ${ }^{16}$ ) and have the advantage over in vitro assays that physiologically relevant conditions are used.

BtuM $_{\mathrm{Td}}$ binds cobalamin using cysteine ligation. Close to the predicted periplasmic surface of $\mathrm{BtuM}_{\mathrm{Td}}$, we found well-defined electron density (Supplementary Figure 5) representing a bound $\mathrm{Cbl}$ molecule. The binding mode of $\mathrm{Cbl}$ in the crystal structure (Fig. 2a) is striking for two reasons. First, the essential Cys80 is the $a$-axial ligand of the cobalt ion. To our knowledge, cobalt coordination by cysteine has not been observed in any other Cblbinding protein of known structure. Binding of cysteine to cobalt in a corrinoid has been hypothesized for the mercury methylating enzyme $\mathrm{HgcA}^{17}$ and observed in a synthetic cyclo-decapeptide, but in the latter case the residue replaced the $\beta$-ligand ${ }^{18}$.

Second, $\mathrm{Cbl}$ is bound to $\mathrm{BtuM}_{\mathrm{Td}}$ in the base-off conformation in which the 5,6-dimethylbenzimidazole moiety does not bind to the cobalt ion (Fig. 2a). In contrast, at physiological $\mathrm{pH}$ the conformation of free $\mathrm{Cbl}$ in aqueous solution is base-on with the 5,6-dimethylbenzimidazole moiety coordinated to the cobalt ion in the $\alpha$-axial position ${ }^{1}$ (Fig. 1a). The base-off conformation has been found only in a subset of Cbl-containing enzymes, but not in Cbl-binding proteins without enzymatic activity ${ }^{1}$, such as the periplasmic substrate-binding protein $\mathrm{BtuF}^{19}$, the outer 
a

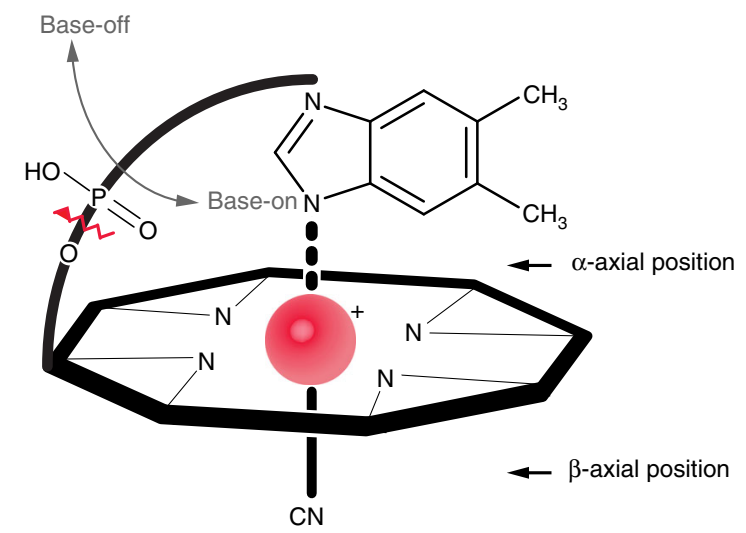

C

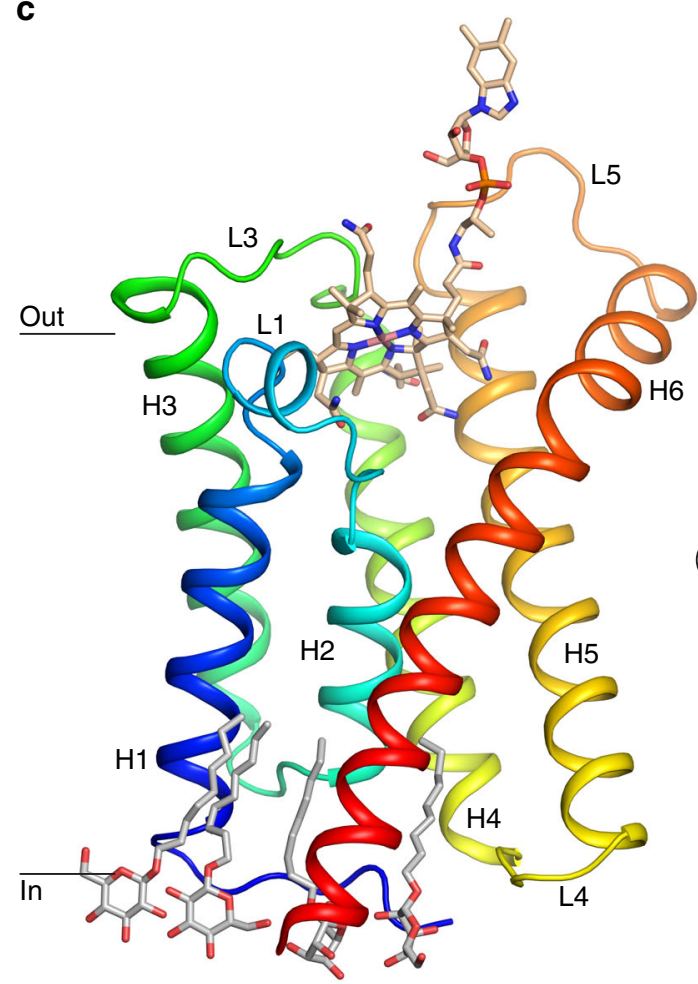

b
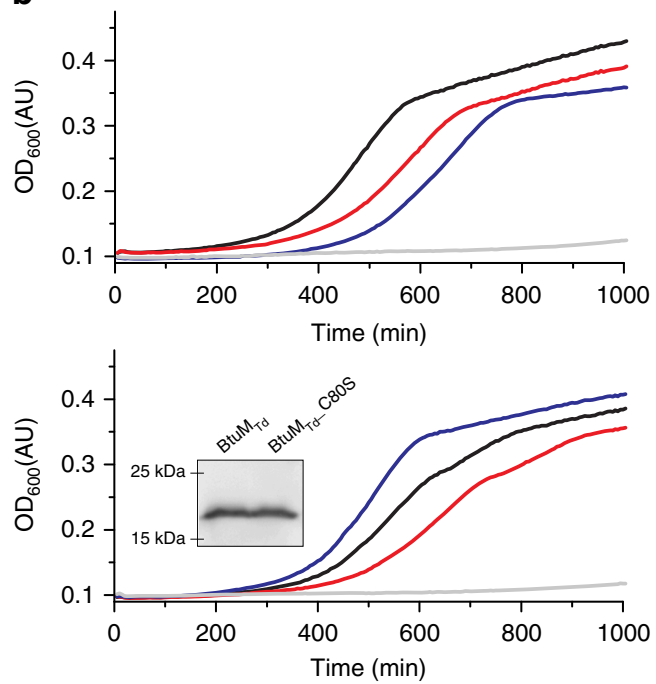
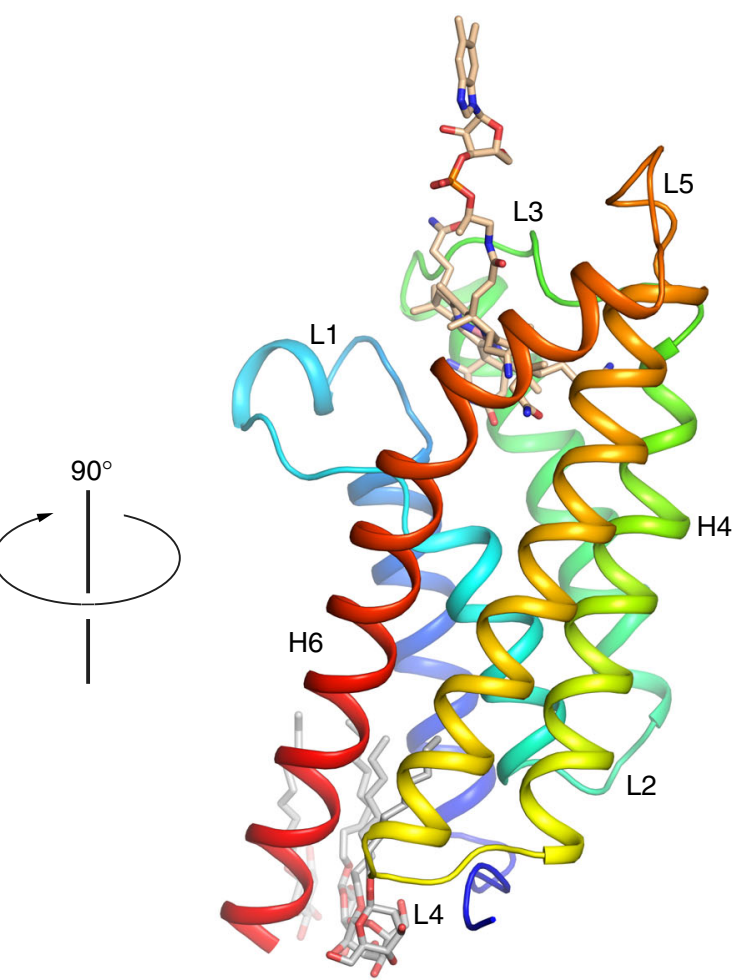

Fig. 1 Function and structure of BtuM $\mathrm{Td}_{\mathrm{d}}$ a Schematic representation of cobalamin (Cbl) showing the corrinoid ring with the central cobalt ion (red). The ligand at the $\beta$-axial position is in this case a cyano-group, but differs in various Cbl variants (Supplementary Figure 1a, b). The ligand at the $\alpha$-axial position (base-on conformation) is the 5,6-dimethylbenzimidazole base, which is covalently linked to the corrinoid ring. When this coordination is lost, Cbl is termed base-off. Cbi lacks the 5,6-dimethylbenzimidazole base (indicated by the zigzagged red line). b Growth assays with $E$. coli $\Delta$ FEC was conducted in the presence of $50 \mu \mathrm{g} \mathrm{ml}^{-1}$ L-methionine or $1 \mathrm{nM} \mathrm{Cbl}$. Additional experiments in the presence of different Cbl concentration are shown in Supplementary Figure $2 f$ and $g$. All growth curves are averages of nine experiments (three biological triplicates, each with three technical replicates). Top panel: cells containing the empty expression vector (pBAD24) in the presence of methionine (blue line) or Cbl (grey line) and cells expressing the BtuCDF system (black and red lines, respectively). Bottom panel: cells expressing BtuM $\mathrm{M}_{\mathrm{Td}}$ (black and red lines) or mutant BtuM $\mathrm{M}_{\mathrm{T}} \mathrm{C} 8 \mathrm{OS}$ (blue and grey) in the presence of methionine and $\mathrm{Cbl}$, respectively. The inset displays a western blot showing that the mutant is expressed to wild-type levels (the full-length western blot can be found in Supplementary Figure $2 \mathrm{~h}$ ). c The structure of BtuM $\mathrm{T}_{\mathrm{T}}$ in cartoon representation, coloured from blue ( $\mathrm{N}$ terminus) to red (C terminus) and viewed from the membrane plane. $\alpha$-helices (H1-6) and connecting loops ( $\mathrm{L} 1-5)$ are indicated. $\mathrm{Cbl}$ is shown in stick representation with carbon atoms coloured wheat, the oxygen and nitrogen atoms in red and blue, respectively, the cobalt ion in pink. Four $n$-nonyl- $\beta$-D-glucopyranoside detergent molecules are also shown in stick representation (carbons in light grey)

membrane transporter $\mathrm{BtuB}^{20}$, and human Cbl-carriers intrinsic factor $^{21}$, haptocorrin 22 and transcobalamin ${ }^{23}$. Enzymes that bind $\mathrm{Cbl}$ with the base-off conformation usually use a histidine residue as the $\alpha$-axial ligand. In this way, the reactivity of the cobalt at the $\beta$-axial position is altered, allowing among others a variety of methyl-group transfer reactions ${ }^{1}$. Therefore, the base-off binding mode by BtuM $_{\mathrm{Td}}$ could indicate that the protein may exhibit enzymatic activity. 


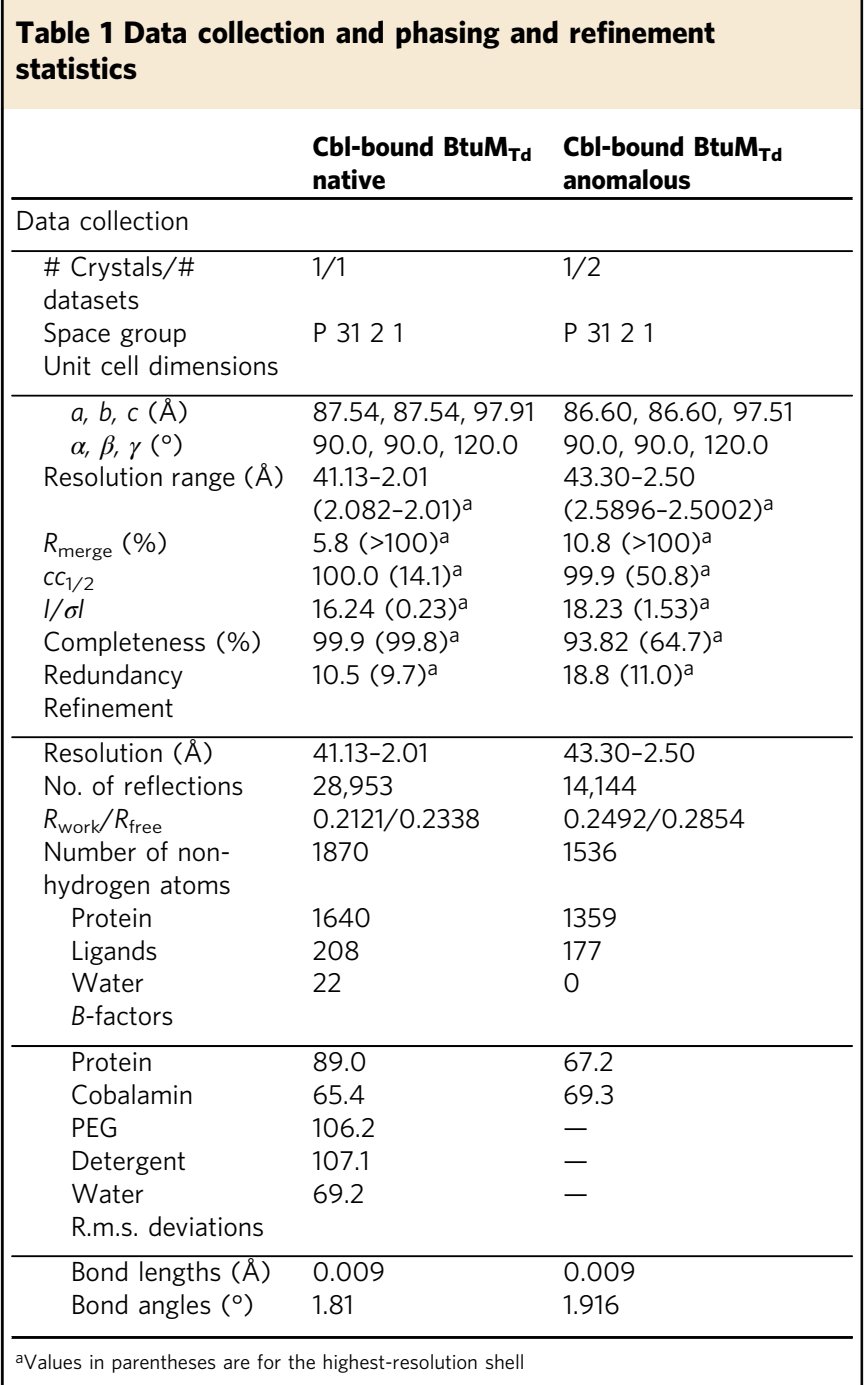

$B_{\text {BtuM }}$ catalyses decyanation of vitamin B12. Indeed, the structure of $\mathrm{BtuM}_{\mathrm{Td}}$ suggests that the protein can catalyse chemical modification of the substrate. We co-crystallized $\mathrm{BtuM}_{\mathrm{Td}}$ with cyano-Cbl, which contains a cyano-group as the $\beta$-ligand ${ }^{1,4}$. Cyano-Cbl is the most stable form of vitamin $\mathrm{B}_{12}{ }^{4}$ but, despite the tight binding of the $\beta$-ligand, in the crystal structure the cyano-group is absent indicating protein-mediated decyanation. Consistent with decyanation and the presence of a cysteine ligand in $\mathrm{BtuM}_{\mathrm{Td}}$, the absorbance spectrum of Cbl-bound $\mathrm{BtuM}_{\mathrm{Td}}$ showed pronounced differences compared to that of free $\mathrm{Cbl}^{18,24}$ (Fig. 2b). The characteristic absorption peak at $361 \mathrm{~nm}$ of $\mathrm{Cbl}$ is absent and two peaks with lower absorption appear around 330 and $370 \mathrm{~nm}$. The absorption between 500 and $580 \mathrm{~nm}$ is lower than in free $\mathrm{Cbl}$, and a new peak at $430 \mathrm{~nm}$ is present.

In place of the cyano-group, the imidazole group of His207 from a neighbouring $\mathrm{BtuM}_{\mathrm{Td}}$ molecule in the crystal is located at the $\beta$-axial position. His207 is the last histidine residue of the $\mathrm{His}_{8}$ affinity-tag (His-tag) engineered at the $\mathrm{C}$ terminus of the protein (Supplementary Figure 6). Because crystal contacts may be nonphysiological and the His-tag is a non-natural addition to the protein, we performed control experiments to exclude the possibility that decyanation is an artefact. First, we showed by mass spectrometry (MS) that the loss of the cyanide does not require crystal formation (Supplementary Figure 7a). Second, we showed that decyanation also occurred by $\mathrm{BtuM}_{\mathrm{Td}}$ with a C- terminal Glu-Pro-Glu-Ala (EPEA)-tag instead of a His-tag (Supplementary Figure 7b). Notably, the EPEA-tagged protein was active in the growth assay and also removal of the His-tag did not affect activity (Supplementary Figure 2b, c). Finally, binding of $\mathrm{Cbl}$ to $\mathrm{BtuM}_{\mathrm{Td}}$ with His-tag or EPEA-tag was accompanied by the same changes in absorption spectrum (Figs. 2b, 3b). Therefore, we conclude that decyanation takes place regardless of crystal formation or presence of a His-tag.

Kinetics of the $B_{t u M_{T d}}$ catalysed decyanation reaction. To study the kinetics of $\mathrm{BtuM}_{\mathrm{Td}}$-catalysed decyanation we used cobinamide (Cbi) instead of $\mathrm{Cbl}$ as substrate. Because Cbi does not contain the 5,6-dimethylbenzimidazole moiety (Fig. 1a), it mimics the base-off conformation of cobalamin, which makes the compound suitable to study decyanation without interference from the slow conversion ${ }^{25}$ of base-on to base-off Cbl. The absorption spectra of Cbl-bound and Cbi-bound $\mathrm{BtuM}_{\mathrm{Td}}$ are almost identical (Fig. 2c), indicating identical coordination of the cobalt ion of $\mathrm{Cbi}$ at the $\alpha$-axial and $\beta$-axial positions. MS analysis showed that binding of $\mathrm{Cbi}$ to $\mathrm{BtuM}_{\mathrm{Td}}$ also results in decyanation (Supplementary Figure 8a). To probe Cbi binding by $\mathrm{BtuM}_{\mathrm{Td}}$, we used isothermal titration calorimetry (ITC), which revealed dissociation constants for the His-tagged and EPEAtagged protein of $0.65 \pm 0.27$ and $0.58 \pm 0.13 \mu \mathrm{M}$ (s.d. of the mean of technical triplicates), respectively (Fig. 3a). It is noteworthy that we were unable to assay for Cbl-binding by ITC. We speculate that the conversion from base-on to base-off $\mathrm{Cbl}$ is so slow ${ }^{25}$ that it may prevent detection of Cbl-binding by ITC. Additionally, the absence of the membrane environment also appears to preclude $\mathrm{Cbl}$ binding to purified $\mathrm{BtuM}_{\mathrm{Td}}$, as binding was observed only when the substrate was added before solubilisation (Fig. 2b, c, Supplementary Figure 9).

Because binding of cyanide to cobinamide causes a decrease in absorbance at $330 \mathrm{~nm}$ and an increase at $369 \mathrm{~nm}^{24}$, we expected the opposite spectral changes upon decyanation. Addition of excess of apo-BtuM $\mathrm{T}_{\mathrm{Td}}$ (Supplementary Figure 10a and b) to a solution of $\mathrm{Cbi}$ indeed revealed time-dependent changes in absorbance consistent with a decyanation reaction (Fig. 3b, c). Decyanation occurred with an apparent time constant of $\tau=12 \pm 0.7 \mathrm{~min}$ (s.d. from technical triplicates, Fig. 3c), which is comparable to the rate observed in the human decyanating enzyme $\mathrm{CblC}^{25,26}$. We also tested Cbi binding and decyanation using mutant proteins C80A and C80S. While these mutants were unable to bind $\mathrm{Cbl}$, they remained capable of binding $\mathrm{Cbi}$ as demonstrated by co-purification of the molecule with the protein (Supplementary Figure 10c, d). We measured the affinity of BtuM $_{\mathrm{Td} \_} \mathrm{C} 80 \mathrm{~S}$ to Cbi with ITC and found a dissociation constant of $5.6 \pm 2.8 \mu \mathrm{M}$ (s.d. of the mean of technical triplicates), which is an order of magnitude weaker than the wild-type (WT) protein. The absorbance spectra of Cbi bound to the mutant proteins showed the characteristic features for cyano-Cbi, indicating that decyanation was abolished (Supplementary Figure 10c, d). Consistently, the decyanation assay with $\mathrm{BtuM}_{\mathrm{Td}} \mathrm{C} 80 \mathrm{~S}$ did not reveal the slow spectral changes observed for the WT protein (Fig. 3b, c). These results show that Cys80 is required for decyanation of $\mathrm{Cbi}$ and that binding and modification of the substrate are separate events: fast binding (detected by ITC) is followed by slow modification. The lack of detectable binding of $\mathrm{Cbl}$ to $\mathrm{BtuM}_{\mathrm{Td}} \mathrm{C} 80 \mathrm{~S}$ (measured by lack of co-purification, Supplementary Figure 10c, d) may indicate that the cysteine is also required for base-on to base-off conversion, and that the base-on conformer binds with too low affinity for detection by co-purification. To understand $\mathrm{BtuM}_{\mathrm{Td}}$-catalysed decyanation of $\mathrm{Cbl}$ and $\mathrm{Cbi}$ in more detail, we mutated conserved amino acids $\mathrm{H} 28$, D67, Y85, and R153 located in the binding pocket 

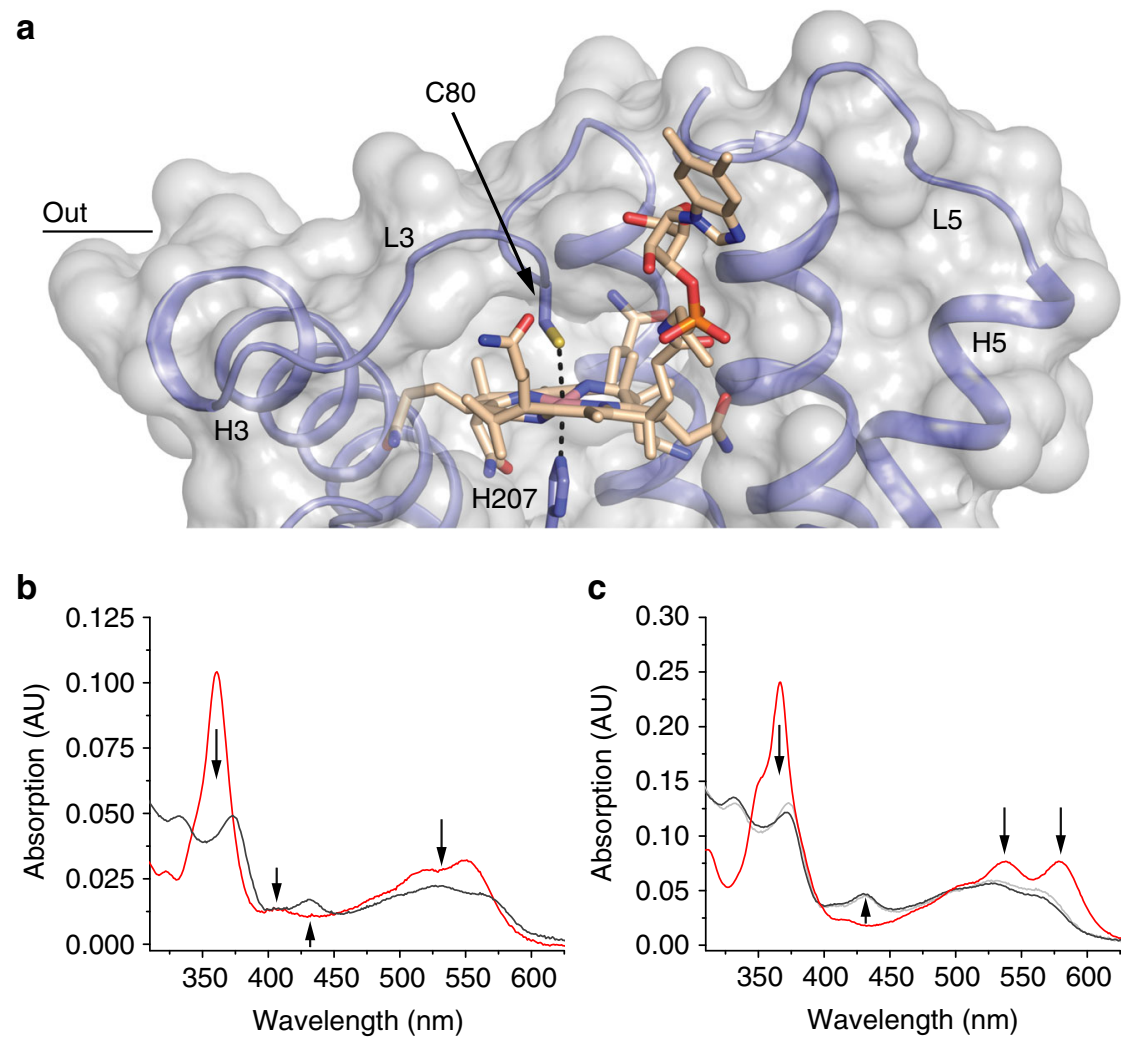

Fig. 2 Binding of vitamin B12 by BtuM $\mathrm{M}_{\mathrm{Td}}$. a Transparent surface representation (light grey) of the binding pocket of BtuM $\mathrm{M}_{\mathrm{Td}}$ with bound $\mathrm{Cbl}$. The protein backbone is shown in blue. The Co-ion is coordinated by Cys80 located in L3 (Co to sulphur distance $2.7 \AA$ ) and His207 (Co to nitrogen distance $2.4 \AA$ ) from a neighbouring symmetry mate (Supplementary Figure 6). A complete description of the interactions of BtuM $\mathrm{M}_{\mathrm{Td}}$ with its substrate can be found in Supplementary Figure 12. b The spectrum of BtuM $\mathrm{M}_{\mathrm{Td}} \mathrm{cH}$ His8-bound $\mathrm{Cbl}(4.3 \mu \mathrm{M}$, black line) compared to unbound cyano-Cbl $(2.4 \mu \mathrm{M}$, red line). The regions of the spectrum with major changes are indicated with arrows. c Same as $\mathbf{b}$ but with Cbi bound to the protein ( $9.2 \mu \mathrm{M}$ black line), compared to unbound dicyano-Cbi ( $9 \mu \mathrm{M}$, red line). The regions of the spectrum with major changes are indicated with arrows. For comparison, a scaled spectrum of $\mathrm{Cbl}$ bound to $B_{\text {tuM }}$ (light grey line) from $\mathbf{b}$ is included, showing that the spectrum of both substrates bound to the protein is virtually the same, indicating the same binding mode

(Supplementary Figure 3b). Mutant D67A could not be purified, and was not analysed further. Cbl-bound mutants H28A, Y85L, and R153A displayed the same spectral properties as the WT protein (Supplementary Figure 11a), and MS analysis showed that the binding of $\mathrm{Cbl}$ was accompanied by decyanation, indicating that the conserved residues are not essential for the reaction (Supplementary Figure 11b-d). Finally, to exclude that $\mathrm{BtuM}_{\mathrm{Td}}$ is merely a decyanating enzyme, and that the potential reaction product hydroxyl-Cbl is subsequently transported by another protein, we show that $\mathrm{BtuM}_{\mathrm{Td}}$ also mediates uptake of hydroxyl$\mathrm{Cbl}$ in the growth assay (Supplementary Figure 2d, e).

\section{Discussion}

We showed in vivo that $\mathrm{BtuM}_{\mathrm{Td}}$ is a vitamin $\mathrm{B} 12$ transporter, which is consistent with the predictions based on bioinformatics analysis ${ }^{5}$. Our work sheds light on the diversity of transport systems used for the uptake of vitamin B12. The outer membrane transporter BtuB is a TonB-dependent active transporter, which uses a different mechanism of transport than inner membrane proteins ${ }^{1,20}$. The well-studied inner membrane type II $A B C$ transporter BtuCDF uses hydrolysis of ATP to pump Cbl into the cell like the ECF-transporter, ECF-CbrT ${ }^{27}$. Both systems require a substrate-binding protein and are multiprotein complexes $7,8,27,28$. $\mathrm{BtuM}_{\mathrm{Td}}$ on the other hand, must operate by a different mechanism because the protein lacks accessory components and the expected ATPase motifs of ABC transporters ${ }^{10}$. BtuM $\mathrm{Td}$ structurally resembles the S-components of ECF transporters. In
ECF transporters, the S-components bind the transported substrate with high affinity and then associate with an ECF-module for energizing transport. During the transport cycle, the Scomponents rotate (topple over) in the membrane to bring the substrate from the outside to the cytoplasm. We hypothesize that $\mathrm{BtuM}_{\mathrm{Td}}$ mediates the translocation of $\mathrm{Cbl}$ through the membrane by a similar toppling mechanism. Because $\mathrm{BtuM}_{\mathrm{Td}}$ does not require an ECF-module, the transport mode may be facilitated diffusion along the concentration gradient of the substrate. In $T$. denitrificans and most other BtuM hosts, the $\mathrm{BtuM}_{\mathrm{Td}}$ gene colocalizes with $b t u R$, which encodes for the cobalamin adenosyltransferase BtuR. This enzyme catalyses the synthesis of 5 -deoxyadenosyl-cobalamin and would offer a mechanism of metabolic trapping, similar to what has been proposed for other vitamin transporters in bacteria ${ }^{29}$.

Our work provides experimental evidence for a binding mode of Cbl, in which cysteine ligation and the base-off conformation are linked. This binding mode leads to decyanation of cyano-Cbl, for which we propose a reductive decyanation mechanism, which depends on Cys $80^{17,18}$ (Supplementary Figure $8 \mathrm{~d}$ ). The proposed decyanation mechanism differs from the mechanism used by $\mathrm{CblC}$, where a flavin acts as reducing agent. In $\mathrm{CblC}$, the flavin donates two electrons resulting in the reductive decyanation $\left(\mathrm{CN}^{-}\right)$and the reduction of the Coion $^{25,26}$. For BtuM $\mathrm{Td}_{\mathrm{Td}}$, cysteine-catalysed reductive decyanation would only result in the release of $\mathrm{CN}^{-}$, but not in the reduction of the Co-ion. 
a

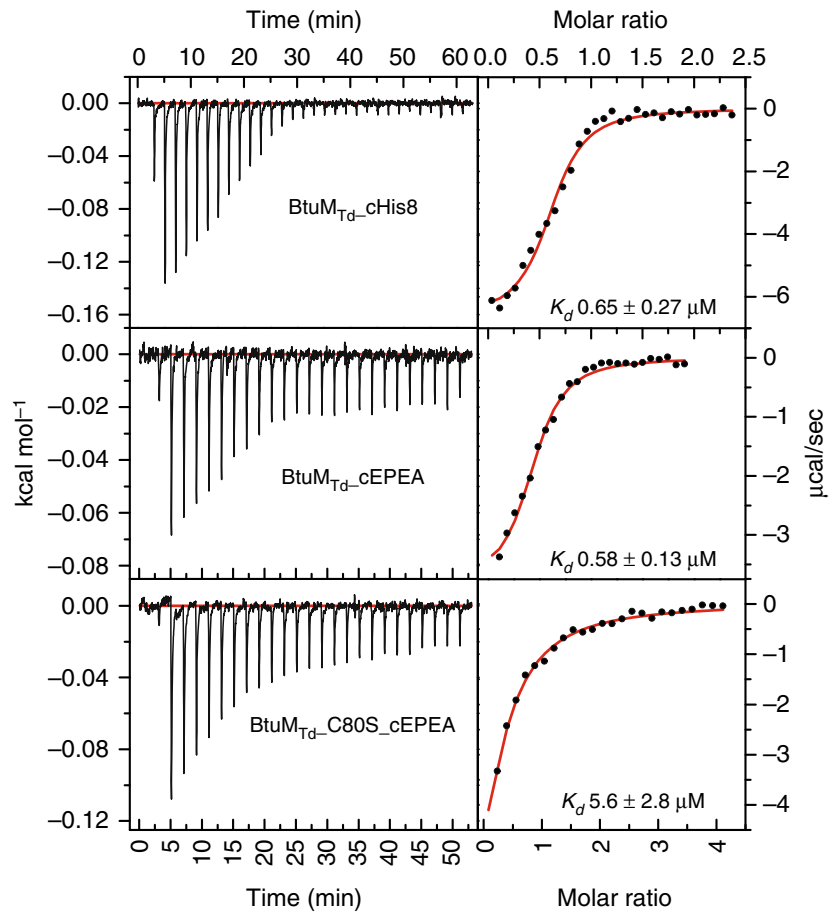

b
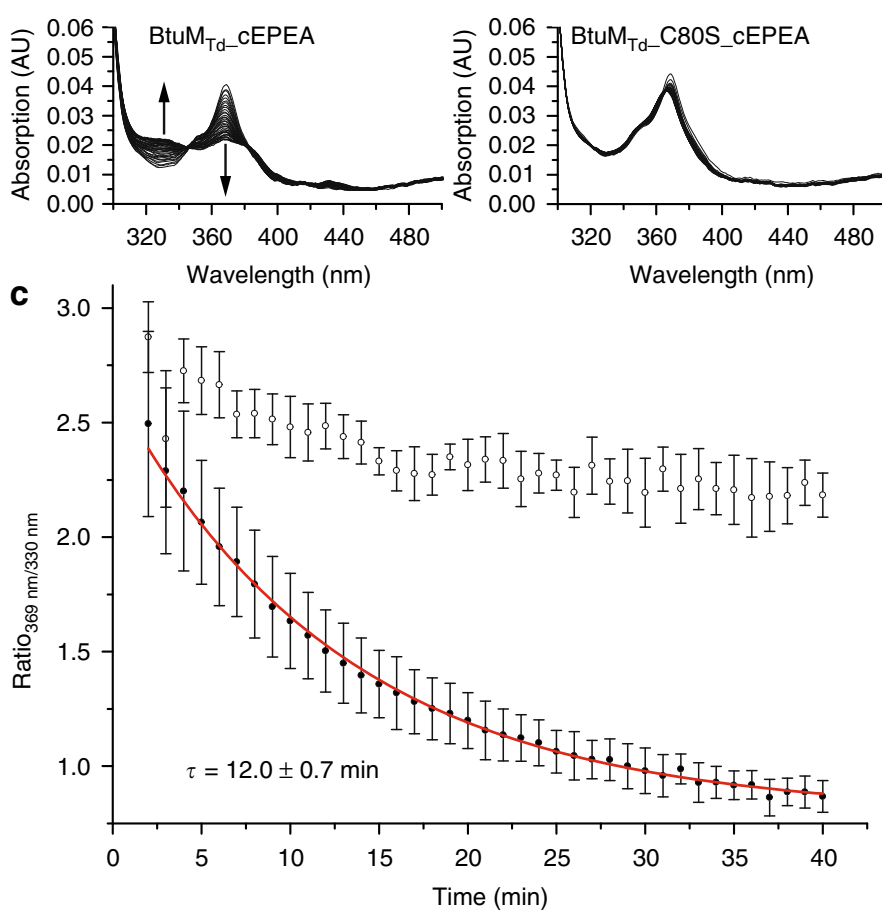

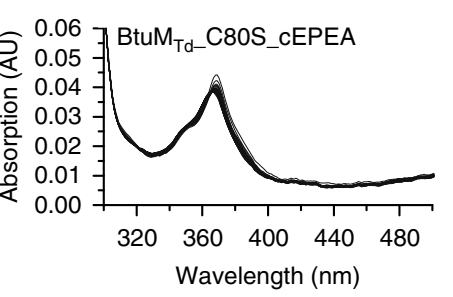

Fig. 3 Cobinamide $(\mathrm{Cbi})$ binding to BtuM $\mathrm{M}_{\mathrm{Td}}$ and $\mathrm{BtuM}_{\mathrm{Td}}$-catalysed decyanation. a Representative ITC-measurements of differently tagged BtuM $\mathrm{M}_{\mathrm{Td}}$ constructs. BtuM $\mathrm{M}_{\mathrm{Td}}$ with a $\mathrm{C}$-terminal His-tag binds $\mathrm{Cbi}$ with a $K_{\mathrm{d}}$ value of $0.65 \pm 0.27 \mu \mathrm{M}$ (top). EPEA-tagged BtuM $\mathrm{M}_{\mathrm{T} d}$ binds $\mathrm{Cbi}$ with essentially the same affinity of $K_{d} 0.58 \pm 0.13 \mu \mathrm{M}$ (middle). For the EPEA-tagged mutant version BtuM ${ }_{T d}$ C $80 S K_{d}=5.6 \pm 2.8 \mu \mathrm{M}$ (bottom). All ITC experiments were performed as technical triplicates, error is s.d. $\mathbf{b}$ Decyanation of Cbi catalysed by EPEA-tagged BtuM $\mathrm{M}_{\mathrm{T} \text {. Upon addition of an excess of BtuMTd }}$ to Cbi, the substrate is slowly decyanated, which can be followed spectroscopically (left) with the main spectral changes indicated by the arrows. The mutant BtuM $_{T_{1} \_}$C80S, did not catalyse decyanation (right). c Quantification (error bars are s.d. of technical triplicates) of decyanation reveals that the process is slow. The ratio of the absorption at $369 \mathrm{~nm}$ over $330 \mathrm{~nm}$ of BtuM $_{\mathrm{Td}}$ (black dots) was plotted as function of time. A mono-exponential decay function was fitted to the data (red line) to extract $\tau=12 \pm 0.7 \mathrm{~min}$ (s.d. of technical triplicates), which is comparable to the decyanation rate of the His-tagged protein and the process follows pseudo-first order kinetics (Supplementary Figure 8b, c). The ratio of absorption obtained with the cysteine mutant (open dots), which does not catalyse decyanation, is shown for comparison

Finally, BtuM $\mathrm{Td}_{\mathrm{Td}}$ likely combines two functions: transport of the substrate into the bacterial cell, and chemical modification of the substrate. Such combined functionality rarely occurs in transporters, and has been observed only in phosphotransferase systems ${ }^{30}$. However, in that case the modification (phosphorylation) takes place on the cytoplasmic side of the membrane ${ }^{30}$, whereas BtuM $_{\mathrm{Td}}$ appears to modify on the periplasmic side of the membrane. Internalisation of decyanated vitamin B12 may be relevant because environmental cyano-Cbl exists ${ }^{26}$. A combination of decyanation and transport activity would make cyano-Cbl directly accessible for conversion into physiological forms, for example, by BtuR.

\section{Methods}

Bioinformatic identification of BtuM homologues and ECF-modules. The amino acid sequence of BtuM $_{\mathrm{Td}}$ was used as a search query using the iterative jackHMMer algorithm (default settings) with the reference proteome database ${ }^{31}$ until the search converged leading to 131 hits. Within the genomes of the identified 131 organisms, we screened for the presence of an ECF-module using the pHMMer algorithm (default settings) ${ }^{31}$ with the amino acid sequence of the transmembrane component (ECF-T) from Lactobacillus delbrueckii ${ }^{14}$ as a search query. Additionally, we used the SEED viewer (http://pseed.theseed.org) to verify the absence of any ECFtransporter in a subset of organisms (46 present in the SEED database) and also used this tool to find all $\mathrm{ABC}$ transporters in T. denitrificans to verify that none of these are an ECF-transporter.

Molecular methods. For expression in E. coli $\mathrm{MC1} 061^{32}$ a codon optimized version (Invitrogen) of btuM (Tbd_2719) from Thiobacillus denitrificans ATCC25259 with a C-terminal eight histidine affinity-tag or EPEA-tag was used and introduced into pBAD $24^{33}$ with NcoI and HindIII restriction sites. A single glycine (Gly2) was introduced to be in-frame with the start-codon of the NcoI restriction site. Single amino acid substitutions and removal of the affinity tag were conducted using sitedirected mutagenesis. The complementation plasmid for expression of BtuC and BtuF was constructed using Gibson Assembly following the standard procedure (NEB). All constructs were checked for correct sequences by DNA sequencing. All primers are listed in Supplementary Table 2.

Construction of the $\triangle$ FEC strain. E. coli $\triangle \mathrm{FEC}$, was constructed by P1-mediated generalized transduction ${ }^{27,34,35}$. In short: E. coli JW0154 $\left(\Delta b t u F:: K^{R}\right)$ was used as the basis for construction of $E$. coli $\triangle \mathrm{FEC}$. The kanamycin resistance cassette was removed using the FLP-recombinase ${ }^{36}$. The metE::Km ${ }^{R}$ locus from E. coli JW3805 and the $\triangle b t u C:: \mathrm{Km}^{R}$ locus of E. coli JW1701 was introduced ${ }^{34,35}$, resulting in E. coli $\Delta$ FEC $\left(\Delta b t u F, \Delta m e t E, \Delta b t u C:: K m^{R}\right)$. Colony PCRs based on three primer pairs ${ }^{27}$ were used to verify $\mathrm{Km}^{R}$-insertions, FLP-recombinase-mediated removal of $\mathrm{Km}^{R}$ markers and absence of genomic duplications (Supplementary Figure 13).

Growth assays. The strains carrying various expression vectors were grown overnight at $37^{\circ} \mathrm{C}$ on LB-agar plates supplemented with $25 \mu \mathrm{g} \mathrm{ml}{ }^{-1}$ kanamycin and $100 \mu \mathrm{g} \mathrm{ml}^{-1}$ ampicillin. M9 minimal medium $\left(47.7 \mathrm{mM} \mathrm{Na}{ }_{2} \mathrm{HPO}_{4} \times 12 \mathrm{H}_{2} \mathrm{O}\right.$, $17.2 \mathrm{mM} \mathrm{KH}_{2} \mathrm{PO}_{4}, 18.7 \mathrm{mM} \mathrm{NH} 4 \mathrm{Cl}, 8.6 \mathrm{mM} \mathrm{NaCl}$ ) was supplemented with $0.4 \%$ glycerol, $2 \mathrm{mM} \mathrm{MgSO}_{4}, 0.1 \mathrm{mM} \mathrm{CaCl}_{2}, 100 \mu \mathrm{g} \mathrm{ml}^{-1}$ L-arginine, $25 \mu \mathrm{g} \mathrm{ml}^{-1}$ kanamycin and $100 \mu \mathrm{g} \mathrm{ml}^{-1}$ ampicillin. A single colony was picked and used to inoculate an M9-medium pre-culture supplemented with $50 \mu \mathrm{g} \mathrm{ml}^{-1} \mathrm{~L}$-methionine (Sigma-Aldrich). The pre-culture was grown $\sim 24 \mathrm{~h}$ at $37^{\circ} \mathrm{C}$, shaking in tubes with gas-permeable lids (Cellstar), and then used to inoculate the assay medium in a 1:500 ratio. The assay medium was supplemented with $0.00001 \% \mathrm{~L}$-arabinose (Sigma-Aldrich) and either $50 \mu \mathrm{g} \mathrm{ml}^{-1}$ L-methionine, $0.01 \mathrm{nM}, 1 \mathrm{nM}$ and $5 \mathrm{nM}$ cyano-cobalamin (Acros Organics), or $0.1 \mathrm{nM}$ hydroxy-cobalamin (SigmaAldrich). Overall, $200 \mu \mathrm{l}$ medium was added per well of a sterile 96 well plate (Cellstar). Plates were sealed with a sterile and gas-permeable foil (BreatheEasy, Diversified Biotech). The cultures were grown for $1000 \mathrm{~min}$ (1250 $\mathrm{min}$ for $\mathrm{Cbi}$ ) in a BioTek Power Wave 340 plate reader at $37^{\circ} \mathrm{C}$, shaking. The $\mathrm{OD}_{600}$ was measured every $5 \mathrm{~min}$ at $600 \mathrm{~nm}$. All experiments were conducted as technical triplicates 
from biological triplicate. The displayed growth curves are the averages of all nine curves.

Western blotting. Cells grown in LB-medium were broken in $50 \mathrm{mM} \mathrm{K}-\mathrm{P}_{\mathrm{i}} \mathrm{pH}$ 7.5 supplemented with $10 \%$ glycerol, $1 \mathrm{mM} \mathrm{MgSO}, 1 \mathrm{mM}$ phenylmethylsulfonyl fluoride (PMSF) and DNaseI with glass beads in a tissue lyser at 50 hertz. The lysate was centrifuged for $10 \mathrm{~min}$ at $20,000 \times g$ and $4{ }^{\circ} \mathrm{C}$ and the supernatant was used for further analysis. The samples analysed by SDS-polyacrylamide gel electrophoresis followed by semi-dry western blotting. The primary antibody was mouse anti-Tetra.His Antibody, BSA-free from Qiagen (Cat.No. 34670) and the secondary antibody was anti-mouse IgG (whole molecule)-alkaline phosphatase conjugate antibody from Sigma-Aldrich (Cat.No. A1902-1ML). The dilutions were 1:2000 and 1:10,000, respectively. The full-length blot from Fig. 1 is included (Supplementary Figure $2 \mathrm{~h}$ )

Overexpression and crude membrane vesicle preparation. All $\mathrm{BtuM}_{\mathrm{Td}}$ variants were overexpressed in E. coli MC1061. Overnight pre-cultures in LB-medium supplemented with $100 \mu \mathrm{g} \mathrm{ml}^{-1}$ ampicillin were diluted in a 1:100 ratio and allowed to grow at $37^{\circ} \mathrm{C}$ to an $\mathrm{OD}_{600}$ of $0.6-0.8$. Expression was induced by addition of $0.05 \% \mathrm{~L}$-arabinose for $3 \mathrm{~h}$. Cells were harvested, washed with $50 \mathrm{mM} \mathrm{K}$ $\mathrm{P}_{\mathrm{i}} \mathrm{pH} 7.5$, and broken with a Constant Systems cell disruptor at $25 \mathrm{kpsi}$ in $50 \mathrm{mM}$ K- $\mathrm{P}_{\mathrm{i}}$ pH 7.5 supplemented with $200 \mu \mathrm{M}$ PMSF, $1 \mathrm{mM} \mathrm{MgSO}$ and DNaseI. Cell debris were removed by centrifugation for 30 min with $25,805 \times g$ and $4{ }^{\circ} \mathrm{C}$. The supernatant was centrifuged for $2.5 \mathrm{~h}$ at $158,420 \times g$ (average) and $4{ }^{\circ} \mathrm{C}$ to collect crude membrane vesicles (CMVs). The CMV pellet was homogenized in $50 \mathrm{mM} \mathrm{K}$ $\mathrm{P}_{\mathrm{i}} \mathrm{pH} 7.5$ and used for purification.

Purification of BtuM $\mathbf{M}_{\mathbf{T d}}$ for crystallisation. His-tagged BtuM for crystallisation was solubilised in buffer A (50 mM HEPES/NaOH pH $8,300 \mathrm{mM} \mathrm{NaCl}, 0.05 \mathrm{mM}$ cyano-Cbl, $1 \% n$-dodecyl- $\beta$-maltoside (DDM) and $15 \mathrm{mM}$ imidazole/ $\mathrm{HCl} \mathrm{pH} \mathrm{8.5)}$ for $45 \mathrm{~min}$ at $4{ }^{\circ} \mathrm{C}$ with gentle movement. Unsolubilized material was removed by centrifugation for $35 \mathrm{~min}$ at $219,373 \times \mathrm{g}$ (average) and $4^{\circ} \mathrm{C}$. The supernatant was decanted into a poly-prep column (BioRad) containing $0.5 \mathrm{ml}$ bed volume superflow $\mathrm{Ni}^{2+}$-NTA sepharose (GE healthcare) equilibrated with 20 column volumes (CV) buffer A containing additionally $3 \mathrm{mM}$ dithiotreitol (DTT) and incubated for $1 \mathrm{~h}$ at $4{ }^{\circ} \mathrm{C}$ with gentle movement. Unbound protein was allowed to flow through and the column was washed twice with ten CV buffer A supplemented with $3 \mathrm{mM}$ DTT and $0.35 \% n$-nonyl- $\beta$-D-glucopyranoside (NG) and $60 \mathrm{mM}$ or $90 \mathrm{mM}$ imidazole/ $\mathrm{HCl} \mathrm{pH} \mathrm{8.5.} \mathrm{Bound} \mathrm{protein} \mathrm{was} \mathrm{eluted} \mathrm{from} \mathrm{the} \mathrm{column} \mathrm{in} \mathrm{four} \mathrm{fractions} \mathrm{of}$ $0.5 \mathrm{ml}$ (first) $-0.7 \mathrm{ml}$ (others) with buffer A supplemented with $3 \mathrm{mM}$ DTT $0.35 \%$ $\mathrm{NG}$ and $350 \mathrm{mM}$ imidazole/ $\mathrm{HCl} \mathrm{pH} \mathrm{8.5.} \mathrm{The} \mathrm{sample} \mathrm{was} \mathrm{centrifuged} \mathrm{for} 5 \mathrm{~min}$ at $20,000 \times g$ and $4^{\circ} \mathrm{C}$ to remove aggregates, and then loaded on a SD200 10/300 Increase SEC column (GE healthcare), which was equilibrated with $30 \mathrm{ml}$ buffer B (50 mM HEPES/NaOH pH 8, $100 \mathrm{mM} \mathrm{NaCl}, 0.005 \mathrm{mM}$ cyano-Cbl and $0.35 \% \mathrm{NG}$ ) and eluted in the same buffer while monitoring absorption at 280 and $361 \mathrm{~nm}$.

Purification of His-tagged BtuM $\mathbf{M}_{\mathbf{T d}}$. Purification of His-tagged protein for biochemical analyses was essentially performed as described above with the following adaptations. HEPES was replaced with $50 \mathrm{mM} \mathrm{K}-\mathrm{P}_{\mathrm{i}} \mathrm{pH} 7$ or 7.5 (for ITC and spectral analyses, respectively), NG was replaced with $0.04 \%$ DDM, and $100 \mathrm{mM}$ $\mathrm{NaCl}$ was used throughout. For purification of the apo protein, substrate was omitted from all buffers. For spectral analyses of substrate-bound proteins, substrate was omitted from buffer B.

Purification of EPEA-tagged BtuM $\mathbf{M}_{\mathrm{Td}}$. EPEA-tagged protein was purified as described above with the following adaptations. CaptureSelect ${ }^{\mathrm{TM}}$ C-tagXL Affnity Matrix (Thermo Fisher Scientific) was used. DTT and imidazole were omitted in all steps and $50 \mathrm{mM}$ Tris/ $\mathrm{HCl} \mathrm{pH} 7.5$ was used instead of K- $\mathrm{P}_{\mathrm{i}}$. The column was washed once with $10 \mathrm{CV}$ buffer supplemented with $500 \mathrm{mM} \mathrm{MgCl}_{2}$. Elution was done in four fractions of 0.5 (first) $\mathrm{ml}-0.8 \mathrm{ml}$ (others) in buffer containing $2 \mathrm{M}$ $\mathrm{MgCl}_{2}$.

Crystallisation and phasing and structure determination. $\mathrm{BtuM}_{\mathrm{Td}}$ purified for crystallisation was concentrated to between 1.1 and $1.6 \mathrm{mg} \mathrm{ml}^{-1}$ with a $10,000 \mathrm{kDa}$ cut-off Vivaspin concentrator (Sartorius) at $4000 \times g$ at $2{ }^{\circ} \mathrm{C}$. The initial screening was done using a Mosquito robot (TTP Labtech), and a hit was found after 1 month in the H1 condition (50 mM Tris pH 8.5, 28\% (v/v) PEG400) of the MemGold2 screen (Molecular Dimensions) at $4{ }^{\circ} \mathrm{C}$. Larger and better diffracting pyramid-shaped crystals were obtained at $8^{\circ} \mathrm{C}$ after 3 to 4 weeks in a crystallization buffer containing $25 \mathrm{mM}$ Tris $\mathrm{pH} 8.5$ and 25 to $30 \%$ (v/v) PEG400, $50 \mathrm{mM}$ Tris $\mathrm{pH}$ 8.5 and 27 to $30 \%(\mathrm{v} / \mathrm{v})$ PEG400 or $75 \mathrm{mM}$ Tris $\mathrm{pH} 8.5$ and 29 to $30 \%(\mathrm{v} / \mathrm{v})$ PEG400, using the sitting drop vapour diffusion method (in MRC Maxi 48-well plate) and a 1:1 mixing ratio $(2 \mu \mathrm{l}$ final drop volume) of mother liquor and protein solution. Phases were obtained from crystals that were soaked for $1 \mathrm{~min}$ with 100 $\mathrm{mM}$ Tb-Xo4 ${ }^{37}$ (Molecular Dimensions) mother liquor solution $(0.5 \mu \mathrm{l}$ added directly to the drop). Diffraction data of the native crystals were collected at the Swiss Light Source (SLS) at PXI (X06SA) beamline ( $\lambda=1.000 \AA, T=100 \mathrm{~K})$ and two anomalous diffraction datasets were collected at the European Synchrotron
Radiation Facility (ESRF) at beamline ID23-1 $(\lambda=1.400 \AA$ and $1.476 \AA$, $T=100$ $\mathrm{K})$. Data were processed with $\mathrm{XDS}^{38}$ and the two datasets containing anomalous information were merged and subsequently used to solve the structure with Shel $\mathrm{X}^{39}$. Autobuild ${ }^{40}$ was used to obtain a starting model, which was refined further with Phenix refine ${ }^{41}$ with manual adjustments done in $\operatorname{Coot}^{42}$. The model was used as an input to solve the phase problem for the native dataset, which was carried out with Phaser-MR ${ }^{43}$. The model of the native data was refined iteratively with Phenix refine ${ }^{41}$ and manual adjustments were done in $\mathrm{Coot}^{42}$. The Ramachandran statistics for the final model are $99.47 \%$ for favoured regions, $0.53 \%$ for allowed regions and $0.00 \%$ for outliers. A stereo view of $2 F_{\mathrm{o}}-F_{\mathrm{c}}$ electron density of the entire structure including the backbone trace molecule, the binding pocket and the Cbl-ligand is provided in Supplementary Figure $5 \mathrm{a}-\mathrm{c}$, respectively. All structural figures were prepared with an open-source version of pymol (https:// sourceforge.net/projects/pymol/).

UV-Vis assay to determine decyanation of vitamin B12. All measurements were carried out in a Cary100Bio spectrophotometer (Varian) at room temperature and baseline corrected for buffer B in a quartz cuvette. To monitor the binding of dicyano-Cbi or cyano-Cbl by $\mathrm{BtuM}_{\mathrm{Td}}$ over time, every minute a spectrum was recorded between 260 and $640 \mathrm{~nm}$ for $40 \mathrm{~min}(\mathrm{Cbi}, n=3)$ or every $20 \mathrm{~min}$ for $12 \mathrm{~h}$ $(\mathrm{Cbl}, n=1)$ at room temperature. For this measurement, a molar protein to substrate ratio of 5:1 (Cbi) or 1:1 (Cbl) was used. To obtain the apparent time constant, $\tau$, the absorbance ratio of $369 / 330 \mathrm{~nm}$ was plotted against the time and fitted with a single exponential decay function in Origin 8. Decyanation assays with Cbi were conducted as technical triplicates and errors are standard deviations of the averaged ratios (if not specified otherwise).

ITC measurement with Cbi. Binding of dicyano-Cbi to purified $\mathrm{BtuM}_{\mathrm{Td}}$ was measured on a microcal200 ITC (GE healthcare) in high feedback mode. The cell temperature was set to $25^{\circ} \mathrm{C}$ with a reference power of $9.5 \mathrm{\mu cal} \mathrm{s}^{-1}$. During the measurement, the sample was stirred at $750 \mathrm{rpm}$ and a 15 -fold excess (WT) or 32.5 -fold excess (C80S) of $\mathrm{Cbi}$ in the syringe was used over the protein concentration in the cell. The data was analysed in Origin and experiments were done as technical triplicates $(n=3)$. The obtained dissociation constants were averaged and the error is the standard deviation of the replicates.

Mass spectrometry. BtuM $\mathrm{M}_{\mathrm{Td}}$ variants and mutant proteins were purified as described above. BtuM $_{\mathrm{Td}}$ proteins were diluted in a 1:1 (v/v) ratio with $0.1 \%$ formic acid and $5 \mu \mathrm{l}$ were injected into an Ultimate 3000-UPLC system (Dionex), connected to a Q-Exactive mass spectrometer (Thermo Fisher Scientific) and separated on a $2.1 \mathrm{~mm} \times 50 \mathrm{~mm}$ Acquity UPLC BEHC18, $1.7 \mu \mathrm{m}$ (Waters). Solvent A was $\mathrm{H}_{2} \mathrm{O}$ with $0.1 \%$ formic acid and solvent B was acetonitrile with $0.1 \%$ formic acid The following mobile phase gradient was delivered at a flow rate of $0.6 \mathrm{ml} \mathrm{min}-1$ starting with a mixture of $60 \%$ solvent B for $1 \mathrm{~min}$. Solvent B was increased to $90 \%$ over $5 \mathrm{~min}$ with a linear gradient and kept at this concentration for $5 \mathrm{~min}$. Solvent B was reduced to $60 \%$ in $0.1 \mathrm{~min}$ and kept for $3.9 \mathrm{~min}$ resulting in a total elution time of $15 \mathrm{~min}$. The column temperature was kept constant at $40^{\circ} \mathrm{C}$. The mass spectrometer was operated in positive mode. Full scan MS spectra were acquired for $10 \mathrm{~min}$ from $\mathrm{m} / \mathrm{z} 1000$ to 2000 at a target value of $1 \times 10^{6}$ and a max IT of 500 ms with a resolution of 140,000 at $\mathrm{m} / z 200$. Scans were averaged using Xcalibur 4.0.27.42 Qualbrowser and the isotopically resolved MS spectrum was deconvoluted using the built-in Xtract algorithm.

Data availability. Data supporting the findings of this manuscript are available from the corresponding author upon reasonable request. Atomic coordinates and structure factors for the crystal structure of $\mathrm{BtuM}_{\mathrm{Td}}$ have been deposited in the Protein Data Bank under the accession code 6FFV. The mass spectrometry data have been deposited to the ProteomeXchange Consortium via the PRIDE partner repository with the dataset identifier PXD010024.

Received: 31 May 2018 Accepted: 4 July 2018

Published online: 02 August 2018

\section{References}

1. Gruber, K., Puffer, B. \& Kräutler, B. Vitamin B12-derivatives-enzyme cofactors and ligands of proteins and nucleic acids. Chem. Soc. Rev. 40, 4346 (2011)

2. Raux, E., Schubert, H. L. \& Warren, M. J. Biosynthesis of cobalamin (vitamin B12): a bacterial conundrum. Cell. Mol. Life Sci. 57, 1880-1893 (2000).

3. Banerjee, R. V., Johnston, N. L., Sobeski, J. K., Datta, P. \& Matthews, R. G. Cloning and sequence analysis of the Escherichia coli metH gene encoding cobalamin-dependent methionine synthase and isolation of a tryptic fragment containing the cobalamin-binding domain. J. Biol. Chem. 264, 13888-13895 (1989). 
4. Martens, J. H., Barg, H., Warren, M. \& Jahn, D. Microbial production of vitamin B12. Appl. Microbiol. Biotechnol. 58, 275-285 (2002).

5. Rodionov, D. A., Vitreschak, A. G., Mironov, A. A. \& Gelfand, M. S. Comparative genomics of the vitamin B12 metabolism and regulation in prokaryotes. J. Biol. Chem. 278, 41148-41159 (2003).

6. Roth, J. R., Lawrence, J. G. \& Bobik, T. A. Cobalamin (coenzyme B12): synthesis and biological significance. Annu. Rev. Microbiol. 50, 137-181 (1996).

7. Locher, K. P., Lee, A. T. \& Rees, D. C. The E. coli BtuCD structure: framework for $\mathrm{ABC}$ transporter architecture and mechanism. Science 296, 1091-1098 (2002).

8. Cadieux, N. et al. Identification of the periplasmic cobalamin-binding protein BtuF of Escherichia coli. J. Bacteriol. 184, 706-717 (2002).

9. Davis, B. D. \& Mingioli, E. S. Mutants of Escherichia coli requiring methionine or vitamin B12. J. Bacteriol. 60, 17-28 (1950).

10. Slotboom, D. J. Structural and mechanistic insights into prokaryotic energycoupling factor transporters. Nat. Rev. Microbiol. 12, 79-87 (2014).

11. Rodionov, D. A. et al. A novel class of modular transporters for vitamins in prokaryotes. J. Bacteriol. 91, 42-51 (2009).

12. Erkens, G. B. et al. The structural basis of modularity in ECF-type ABC transporters. Nat. Struct. Mol. Biol. 18, 755-760 (2011).

13. Berntsson, R. P.-A. et al. Structural divergence of paralogous $S$ components from ECF-type ABC transporters. Proc. Natl Acad. Sci. USA 109, 13990-13995 (2012).

14. Swier, L. J. Y. M., Guskov, A. \& Slotboom, D. J. Structural insight in the toppling mechanism of an energy-coupling factor transporter. Nat. Commun. 7, 11072 (2016).

15. Finkenwirth, F., Kirsch, F. \& Eitinger, T. Solitary bio Y proteins mediate biotin transport into recombinant Escherichia coli. J. Bacteriol. 195, 4105-4111 (2013).

16. Genee, H. J. et al. Functional mining of transporters using synthetic selections. Nat. Chem. Biol. 12, 1015-1022 (2016).

17. Zhou, J., Riccardi, D., Beste, A., Smith, J. C. \& Parks, J. M. Mercury methylation by $\mathrm{HgcA}$ : theory supports carbanion transfer to $\mathrm{Hg}(\mathrm{II})$. Inorg. Chem. 53, 772-777 (2014).

18. Duléry, V. et al. A cyclodecapeptide ligand to vitamin B12. Org. Biomol. Chem. 6, 4134-4141 (2008)

19. Borths, E. L., Locher, K. P., Lee, A. T. \& Rees, D. C. The structure of Escherichia coli BtuF and binding to its cognate ATP binding cassette transporter. Proc. Natl Acad. Sci. USA 99, 16642-16647 (2002).

20. Shultis, D. D., Purdy, M. D., Banchs, C. N. \& Wiener, M. C. Outer membrane active transport: structure of the BtuB:TonB complex. Science 312, 1396-1399 (2006).

21. Mathews, F. S. et al. Crystal structure of human intrinsic factor: cobalamin complex at 2.6-A resolution. Proc. Natl Acad. Sci. USA 104, 17311-17316 (2007).

22. Furger, E., Frei, D. C., Schibli, R., Fischer, E. \& Prota, A. E. Structural basis for universal corrinoid recognition by the cobalamin transport protein haptocorrin. J. Biol. Chem. 288, 25466-25476 (2013).

23. Wuerges, J., Geremia, S., Fedosov, S. N. \& Randaccio, L. Vitamin B12 transport proteins: crystallographic analysis of beta-axial ligand substitutions in cobalamin bound to transcobalamin. IUBMB Life 59, 722-729 (2007).

24. Blackledge, W. C. et al. New facile method to measure cyanide in blood. Anal. Chem. 82, 4216-4221 (2010).

25. Koutmos, M., Gherasim, C., Smith, J. L. \& Banerjee, R. Structural basis of multifunctionality in a vitamin B12 -processing enzyme. J. Biol. Chem. 286, 29780-29787 (2011).

26. Kim, J., Gherasim, C. \& Banerjee, R. Decyanation of vitamin B12 by a trafficking chaperone. Proc. Natl Acad. Sci. USA 105, 14551-14554 (2008).

27. Santos, J. A. et al. Functional and structural characterization of an ECF-type ABC transporter for vitamin B12. Elife 7, e35828 (2018).

28. Hvorup, R. N. et al. Asymmetry in the structure of the ABC transporterbinding protein complex BtuCD-BtuF. Science 317, 1387-1390 (2007).

29. Jaehme, M., Guskov, A. \& Slotboom, D. J. Crystal structure of the vitamin B3 transporter PnuC, a full-length SWEET homolog. Nat. Struct. Mol. Biol. 21, 1013-1015 (2014).

30. Cao, Y. et al. Crystal structure of a phosphorylation-coupled saccharide transporter. Nature 473, 50-54 (2011).

31. Finn, R. D. et al. HMMER web server: 2015 update. Nucleic Acids Res 43, W30-W38 (2015).

32. Casadaban, M. J. \& Cohen, S. N. Analysis of gene control signals by DNA fusion and cloning in Escherichia coli. J. Mol. Biol. 138, 179-207 (1980).

33. Guzman, L. M., Belin, D., Carson, M. J. \& Beckwith, J. Tight regulation, modulation, and high-level expression by vectors containing the arabinose PBAD promoter. J. Bacteriol. 177, 4121-4130 (1995).

34. Miller, J. Experiments in Molecular Genetics (Cold Spring Harbor Laboratory, Cold Spring Harbor, NY, 1972).
35. Thomason, L. C., Costantino, N. \& Court, D. L. E. coli genome manipulation by P1 transduction. Curr. Protoc. Mol. Biol. 1, 17.1-1.17.8 (2007).

36. Datsenko, K. A. \& Wanner, B. L. One-step inactivation of chromosomal genes in Escherichia coli K-12 using PCR products. Proc. Natl Acad. Sci. USA 97, 6640-6645 (2000).

37. Engilberge, S. et al. Crystallophore: a versatile lanthanide complex for protein crystallography combining nucleating effects, phasing properties, and luminescence. Chem. Sci. 8, 5909-5917 (2017).

38. Kabsch, W. XDS. Acta Crystallogr. Sect. D. Biol. Crystallogr. 66, 125-132 (2010).

39. Sheldrick, G. M. A short history of SHELX. Acta Crystallogr. Sect. A Found. Crystallogr. 64, 112-122 (2007)

40. Terwilliger, T. C. et al. Iterative model building, structure refinement and density modification with the PHENIX AutoBuild wizard. Acta Crystallogr. Sect. D. Biol. Crystallogr. 64, 61-69 (2007).

41. Adams, P. D. et al. PHENIX: a comprehensive Python-based system for macromolecular structure solution. Acta Crystallogr. Sect. D. Biol. Crystallogr. 66, 213-221 (2010).

42. Emsley, P., Lohkamp, B., Scott, W. G. \& Cowtan, K. Features and development of Coot. Acta Crystallogr. Sect. D. Biol. Crystallogr. 66, 486-501 (2010).

43. McCoy, A. J. et al. Phaser crystallographic software. J. Appl. Crystallogr. 40, 658-674 (2007).

\section{Acknowledgements}

We appreciate the helpful advice from Dr. Stephanie Ruiz with the practical setup and analysis of the growth assay. We thank Dr. M. Majsnerowska (University of Groningen) for help with the construction of the EPEA-tag expression plasmids, and we would like to thank Prof. Dr. A.J.M. Driessen (University of Groningen) for the use of the ITC. We acknowledge the excellent advice, support and experimental work of the Interfaculty Mass Spectrometry Center at the Faculty of Science and Engineering of the University of Groningen. This work was supported by the European Molecular Biology Organization (EMBO; EMBO Short Term Fellowship ASTF-382-2015 to S. Rempel), the Netherlands Foundation for the Advancement of Biochemistry (SSBN; SSBN Travel Grant to S. Rempel), the Netherlands Organization for Scientific Research (NWO Vici grant 865.11.001 to D.J. Slotboom) and the European Research Council (ERC; ERC Starting Grant 282083 to D.J. Slotboom). For technical support, we acknowledge the beamline personnel of PXI (X06SA) and ID23-1 at SLS and ESRF, respectively.

\section{Author contributions}

D.J.S. conceived and supervised the project. S.R. performed cloning, protein production and purification, E. coli $\triangle \mathrm{FEC}$ strain construction, growth assays, bioinformatic analyses, ITC-measurements, spectral analyses and crystallization trials. E.C. conducted spectral analyses. J.W.d.G. designed and carried out experiments to construct E. coli $\triangle \mathrm{FEC}$. A.G and S.R. collected diffraction data, solved the structure and performed refinement. S.R. and D.J.S. analysed the biochemical and spectroscopic data and wrote the manuscript with input from all other authors.

\section{Additional information}

Supplementary Information accompanies this paper at https://doi.org/10.1038/s41467018-05441-9.

Competing interests: The authors declare no competing interests.

Reprints and permission information is available online at http://npg.nature.com/ reprintsandpermissions/

Publisher's note: Springer Nature remains neutral with regard to jurisdictional claims in published maps and institutional affiliations.

(c) (i) Open Access This article is licensed under a Creative Commons Attribution 4.0 International License, which permits use, sharing, adaptation, distribution and reproduction in any medium or format, as long as you give appropriate credit to the original author(s) and the source, provide a link to the Creative Commons license, and indicate if changes were made. The images or other third party material in this article are included in the article's Creative Commons license, unless indicated otherwise in a credit line to the material. If material is not included in the article's Creative Commons license and your intended use is not permitted by statutory regulation or exceeds the permitted use, you will need to obtain permission directly from the copyright holder. To view a copy of this license, visit http://creativecommons.org/ licenses/by/4.0/.

(C) The Author(s) 2018 